\title{
NUMERICAL SIMULATION AND OPTIMIZATION OF OIL JET LUBRICATION FOR ROTORCRAFT MESHING GEARS
}

\author{
Dai, Y.\#; Wu, W.; Zhou, H. B.; Zhang, J. \& Ma, F. Y. \\ School of Mechanical and Electrical Engineering, Central South University, Changsha 410083, China \\ E-Mail: daiyu_6@aliyun.com (" Corresponding author)
}

\begin{abstract}
Oil jet lubrication performance directly influences the operation, reliability and fatigue life of meshing gears working under high-speed and heavy-load conditions in the main reducer of rotorcraft. An oil-air two-phase mixture flow numerical simulation model for jet lubrication on the surface of a pair of meshing gears was established by the computational fluid dynamics (CFD) simulation code ANSYS/FLUENT. The effects of the spin flow caused by a high-speed rotating gear pair on the jet flow trajectory deviation were considered in the numerical simulation. The oil volume and oil pressure distribution characteristics of the meshing area were obtained and compared according to different nozzle position layouts, and the optimal nozzle position layout was determined to obtain a maximum oil volume and oil pressure. A gear-jet-lubrication experimental system was built in which the meshing surface temperatures were measured by an infrared thermometer; meanwhile, the jet flow trajectories were photographed by a high-speed camera. The experimental and numerical simulation results were mutually validated and proved the proposed optimal design scheme for the nozzle position layout.

(Received, processed and accepted by the Chinese Representative Office.)
\end{abstract}

Key Words: $\quad$ Rotorcraft High-Speed Meshing Gear, Oil Jet Lubrication, Two-Phase Flow Numerical Simulation, Spin-Flow Effect, Optimal Nozzle Position Layout

\section{INTRODUCTION}

Many lubrication points are needed for the main reducer of rotorcraft. Combined with their complex structure and extremely compact internal space, it is difficult to design a good oil jet lubrication scheme. Jet lubrication oil is always blocked from accessing the meshing area due to limited meshing clearance and the rotation of the gears under very high-speed transmission conditions, which inevitably lead to a decrease or the complete removal of lubrication oil in the meshing area. Thus, the operational reliability and fatigue life of the main reducer are greatly decreased.

In traditional oil jet lubrication design, the nozzle is always arranged to aim directly at the meshing area with its jet direction along the tangent line of the gear pitch circle. Multiple parameters, such as the jet distance to the meshing point, the jet angle, and the jet velocity to transmission velocity ratio mainly rely on previous operational experience, which is inefficient and ineffective for optimal oil jet lubrication design.

To investigate performance of the oil jet lubrication for meshing gears, McCain and Alsandor studied the out-of-mesh oil jet lubrication phenomenon and defined the oil jet impingement depth for meshing gears [1]. Akin et al. used a high-speed camera to observe the interactions between the oil jet and rotation, which showed that the generated air flow by high-speed rotating gears has great influences on the oil jet break-up and jet trajectory. The jet impingement depth on the meshing gears was also measured [2]. Furthermore, Townsend and Akin used a finite element method to compute the gear surface temperature under jet lubrication conditions and found that the deeper the oil impingement on the gear surface, the better the cooling effect [3]. Hirt and Nichols proposed a method to simulate the lubrication oil jet on a rotating gear in which the oil trajectory in the computational area could be effectively tracked; a finer grid was required for the computational area for this method [4]. 
Akin and Townsend conducted a series of studies on the oil jet lubrication of spur and helical gears under the into-mesh, out-of-mesh and radial direction conditions. Their study found that the oil jet lubrication effect was not only related to the oil jet parameters and gear transmission parameters but also influenced by the oil jetting position and angle [5-8]. Handschuh performed experiments on closed spiral bevel gear test equipment, varying the oil jetting velocity, jetting angle, etc.; the measured gear body temperatures revealed that the jetting angle significantly influenced the gear temperature increase [9]. Fondelli et al. used a mesh adaptive method to simulate the lubrication oil jet along the radial direction of a high-speed gear; the drag torque generated between the oil and gear interaction was studied, and the effects of the oil jet angle on the drag torque and lubrication performance were obtained [10]. Massini et al. used a visualization method to study the effects of the gear rotating velocity on the lubrication performance for jetting along the radial direction and analysed the broken condition of the jet oil and oil film formation conditions on the gear surface [11]. Wang et al. established a CFD numerical model of a pulse jet system. The flow dynamics of a novel nozzle were analysed to predict the effects of nozzle shape and dimensions on the operational performance in terms of pressure and velocity distribution [12]. $\mathrm{Li}$ et al. and Wang et al. conducted a series of studies on oil jet lubrication performance based on a CFD numerical simulation, which showed that for into-mesh jet lubrication, a small angle deviation to the pinion will result in a better lubrication effect [13-15].

However, the problem of the oil-air two-phase mixture flow distribution characteristics on the meshing areas of a high-speed gear pair and its influencing factors need to be ascertained; furthermore, an optimal nozzle position layout method to obtain an optimal jet lubrication performance is not proposed, thus no specific design scheme is available for oil jet lubrication on rotorcraft high-speed meshing gears. Given these deficiencies, the corresponding numerical simulations and simulated experiments were conducted.

\section{FLUID CONTROL EQUATIONS AND NUMERICAL MODELS}

\subsection{Basic fluid control equations}

a. Mass conservation equation:

$$
\frac{\partial \rho}{\partial t}+\frac{\partial\left(\rho u_{x}\right)}{\partial x}+\frac{\partial\left(\rho v_{y}\right)}{\partial y}+\frac{\partial\left(\rho w_{z}\right)}{\partial z}=0
$$

where $\rho$ is density and $u_{x}, v_{y}$ and $w_{z}$ are the velocity components along the $x, y$ and $z$ directions, respectively.

b. Momentum conservation equation:

$$
\left\{\begin{array}{l}
\rho \frac{d u}{d t}=\rho F_{b x}+\frac{\partial p_{x x}}{\partial x}+\frac{\partial p_{y x}}{\partial y}+\frac{\partial p_{z x}}{\partial z} \\
\rho \frac{d v}{d t}=\rho F_{b y}+\frac{\partial p_{x y}}{\partial x}+\frac{\partial p_{y y}}{\partial y}+\frac{\partial p_{z y}}{\partial z} \\
\rho \frac{d w}{d t}=\rho F_{b z}+\frac{\partial p_{x z}}{\partial x}+\frac{\partial p_{y z}}{\partial y}+\frac{\partial p_{z z}}{\partial z}
\end{array}\right.
$$

where $F_{b x}, F_{b y}$ and $F_{b z}$ are mass force components acting on a unit mass fluid along the $x, y$ and $z$ directions, respectively, and $p$ is the tension component of the fluid internal stress.

c. Energy conversation equation:

$$
\left.\frac{\partial(\rho E)}{\partial t}+\nabla \mathrm{g} V(\rho E+p)=\nabla \mathfrak{q} k_{e f f} \nabla T-\sum_{j} h_{j} J_{j}+\left(\tau_{e f f} \mathrm{~g} V\right)\right]+S_{h}
$$


where $E$ is the sum of the internal energy, kinematic energy and potential energy in the control volume, $k_{\text {eff }}$ is the effective thermal conductivity, $h_{j}$ is the $j^{\text {th }}$ enthalpy, $J_{j}$ is the $j^{\text {th }}$ diffusion flux, and $S_{h}$ contains the endothermic and exothermic heats or the self-defined volume heat sources.

\subsection{Turbulence model}

Based on the standard $k-\varepsilon$ model the constraint equations for turbulence viscosity and dissipation rate are added; its turbulence energy and dissipation rate transport equation are expressed as:

$$
\begin{gathered}
\frac{\partial(\rho k)}{\partial t}+\frac{\partial\left(\rho k u_{i}\right)}{\partial x_{i}}=\frac{\partial}{\partial x_{j}}\left[\left(\mu+\frac{\mu_{t}}{\sigma_{k}}\right) \frac{\partial k}{\partial x_{j}}\right]+G_{k}+G_{b}-\rho \varepsilon-Y_{M} \\
\frac{\partial(\rho \varepsilon)}{\partial t}+\frac{\partial\left(\rho \varepsilon u_{i}\right)}{\partial x_{i}}=\frac{\partial}{\partial x_{j}}\left[\left(\mu+\frac{\mu_{t}}{\sigma_{\varepsilon}}\right) \frac{\partial \varepsilon}{\partial x_{j}}\right]+\rho C_{1} E \varepsilon-\rho C_{2} \frac{\varepsilon^{2}}{k+\sqrt{v \varepsilon}}+C_{1 \varepsilon} \frac{\varepsilon}{k} C_{3 \varepsilon} G_{b}
\end{gathered}
$$

where $G_{k}$ is the turbulent kinetic energy caused by the velocity gradient, $G_{b}$ is the turbulent kinetic energy caused by the buoyancy, $Y_{M}$ is the influence factor of the compressible turbulent fluctuation on the turbulent dissipation rate, and $\sigma_{k}$ and $\sigma_{\varepsilon}$ are the Prandtl number of the turbulent kinetic energy and the turbulent energy dissipation rate, respectively.

\subsection{Multi-phases flow model}

The sum of the volume factions for multi-phased flow is computed as:

$$
\sum_{\alpha=1}^{N} r_{\alpha}=1
$$

where the subscript letter $\alpha$ denotes the fluid phase, $r_{\alpha}$ is the volume fraction of the $\alpha$ phase, and $N$ is the number of the fluid phases. The oil jet lubrication process is a typical air-liquid two-phase flow.

The VOF (Volume of Fluid) model provided in the CFD simulation code ANSYS/ FLUENT is adopted in the simulations, which is suitable for simulating one or more incompatible fluid interfaces.

\section{OIL JET LUBRICATION NUMERICAL SIMULATIONS}

\subsection{Relationships between oil jet impingement depth with oil volume and oil pressure}

A 3D finite element mesh model of a gear pair in a rotorcraft main reducer was established as shown in Fig. 1. Four different nozzle positions were designed and arranged in the simulation models. Table I gives the different jet inclination angles, jet offset distances and corresponding calculated impingement depths for different nozzle position layouts. Two typical nozzle positions numbered as simulation models 1 and 4 in Table I were designed in which the limited nozzle positions resulted in no impingement on the pinion and the big gear, respectively.

The CFD simulation code ANASYS/FLUENT was used to establish an oil-air two-phase mixture flow model and to perform numerical simulations. Figs. 2 and 3 present the oil volume contours and oil pressure distributions for the different simulation models with different nozzle positions shown in Table I. Table II gives the corresponding simulation values with their calculated impingement depths. 


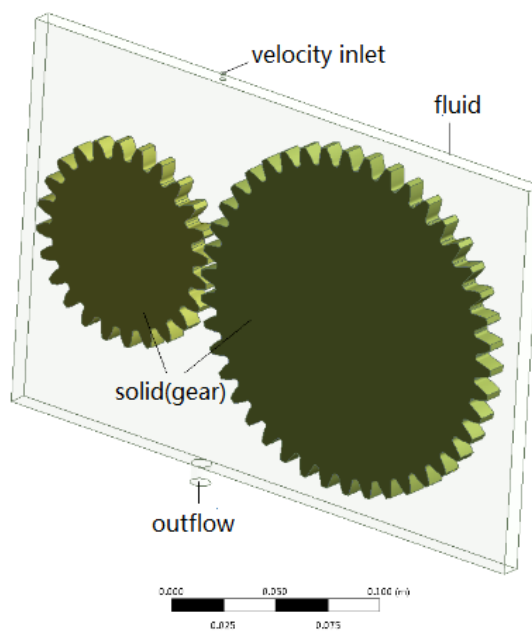

a)

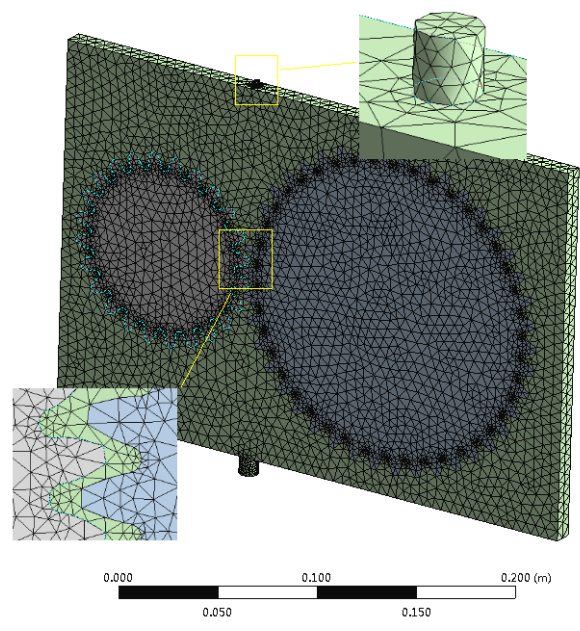

b)

Figure 1: A 3D model for a gear pair: a) internal computation domain; b) finite element mesh model.

Table I: Simulation models with different nozzle position layouts.

\begin{tabular}{|c|c|c|c|c|}
\hline $\begin{array}{c}\text { Simulation } \\
\text { model }\end{array}$ & $\begin{array}{c}\text { Inclination angle } \\
(\text { degree })\end{array}$ & $\begin{array}{c}\text { Offset distance } \\
(\mathrm{mm})\end{array}$ & $\begin{array}{c}\text { Impingement depth } \\
\text { on the pinion }(\mathrm{mm})\end{array}$ & $\begin{array}{c}\text { Impingement depth } \\
\text { on the big gear }(\mathrm{mm})\end{array}$ \\
\hline 1 & 0 & 0 & 0 & 1.14 \\
\hline 2 & 0 & -1.2 & 0.98 & 0.23 \\
\hline 3 & 2.5 & -4.15 & 0.95 & 0.27 \\
\hline 4 & 5 & -8.2 & 1.24 & 0 \\
\hline
\end{tabular}

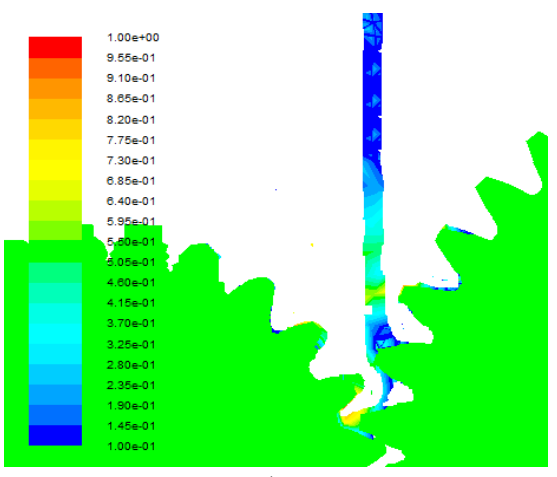

a)

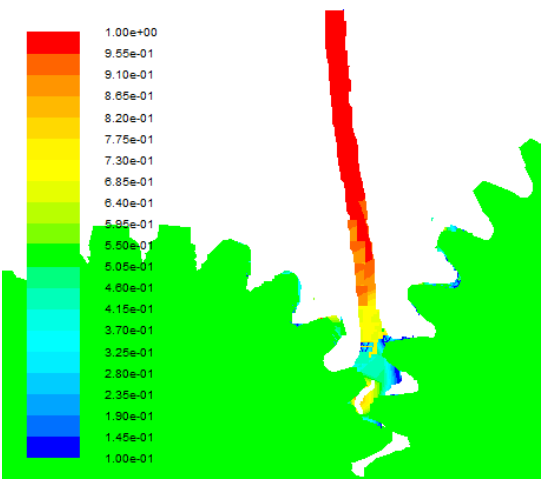

c)

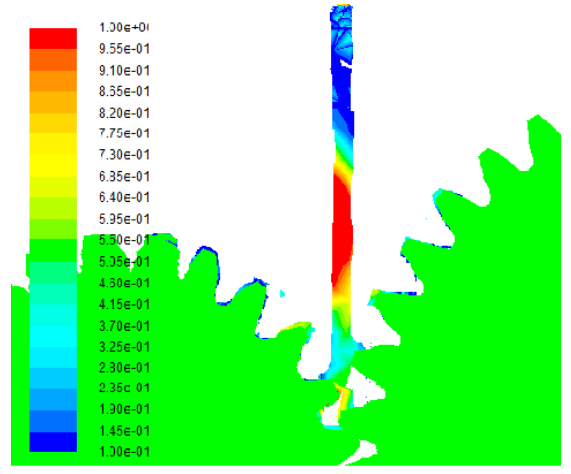

b)

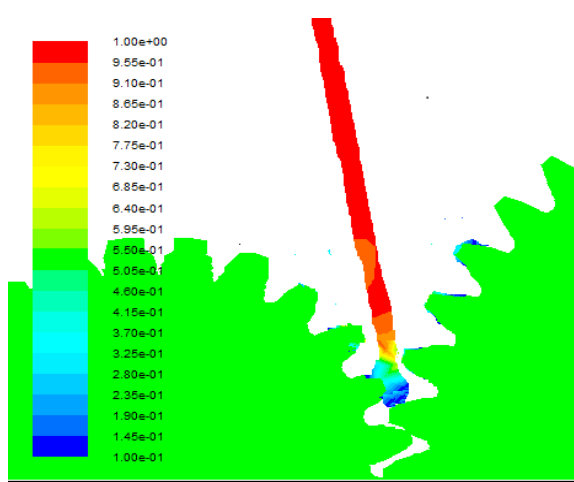

d)

Figure 2: Oil volume contour simulations in the meshing areas for models with different nozzle positions: a) Model 1; b) Model 2; c) Model 3; d) Model 4. 


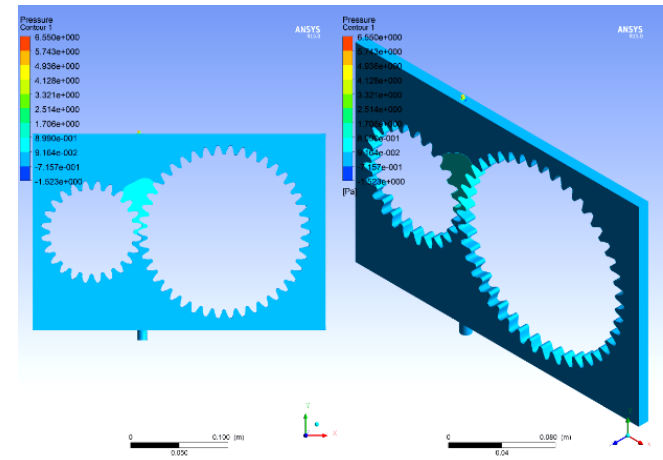

a)

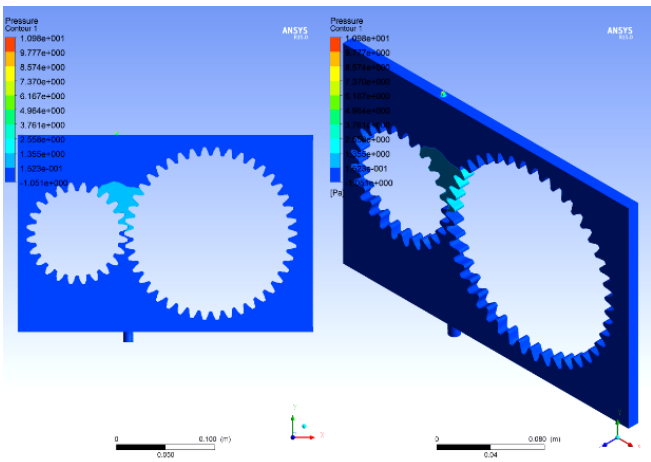

c)

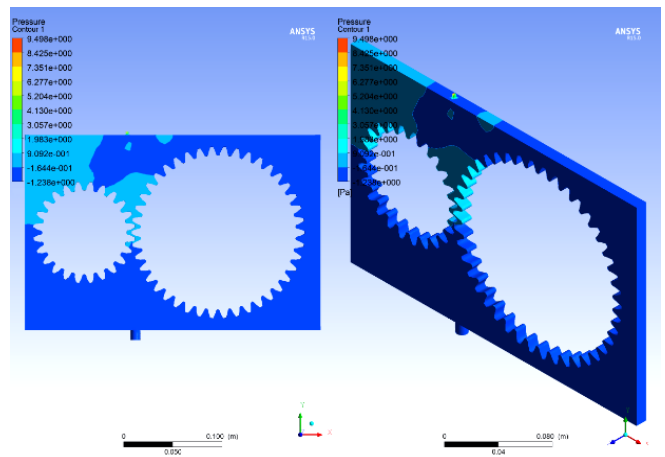

b)

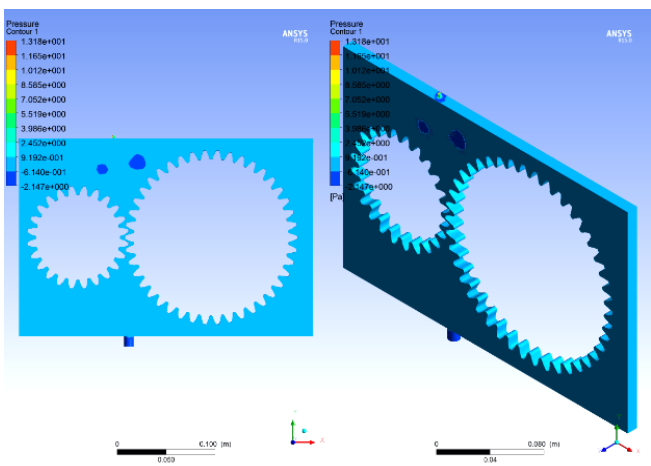

d)

Figure 3: Oil pressure distribution simulations for different models with different nozzle positions: a) Model 1; b) Model 2; c) Model 3; d) Model 4.

Table II: Oil volume and oil pressure simulation results and corresponding impingement depths.

\begin{tabular}{|c|c|c|c|}
\hline $\begin{array}{c}\text { Simulation } \\
\text { model }\end{array}$ & Oil volume & $\begin{array}{c}\text { Oil pressure } \\
(\mathrm{Pa})\end{array}$ & $\begin{array}{c}\text { Impingement depth } \\
(\mathrm{mm})\end{array}$ \\
\hline 1 & 0.067 & 864.5 & 0 \\
\hline 2 & 0.072 & 899.7 & 0.98 \\
\hline 3 & 0.074 & 901.5 & 0.95 \\
\hline 4 & 0.086 & 919.2 & 1.24 \\
\hline
\end{tabular}

It can be seen the jet points on the meshing gear surfaces for the four simulation models are different. For the model without jet inclination angle and without jet offset, as shown in Fig. 2 a, the jet flow will be blocked by the big gear, resulting in a poor lubrication effect for the pinion. When the nozzle was tilted and offset towards the pinion, the impingement depths on the pinion increased and consequently initiated a better lubrication effect. However, the larger inclination angle and offset distance for the nozzle to the pinion leads to no oil jet on the big gear. It can also be concluded that the greater the impingement depth, the higher the oil volume and oil pressure, which results in better lubrication and cooling effects.

\subsection{Influence of spin flow on jet flow trajectory}

The spin flow generated by a rotating gear pair especially under very high-speed conditions should be taken into account in the simulation to ascertain its influence on the jet flow trajectory deviation. The deviation causes the oil not to be sprayed into the meshing area accurately, resulting in a failure of the lubrication and cooling. Fig. 4 shows a group of simulation diagrams when considering the spin-flow effect. Obviously, the oil jet flow will deviate from its predetermined trajectory towards the big gear. 

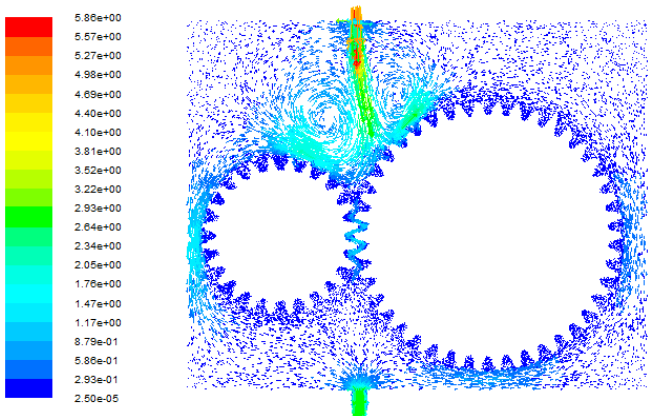

a)
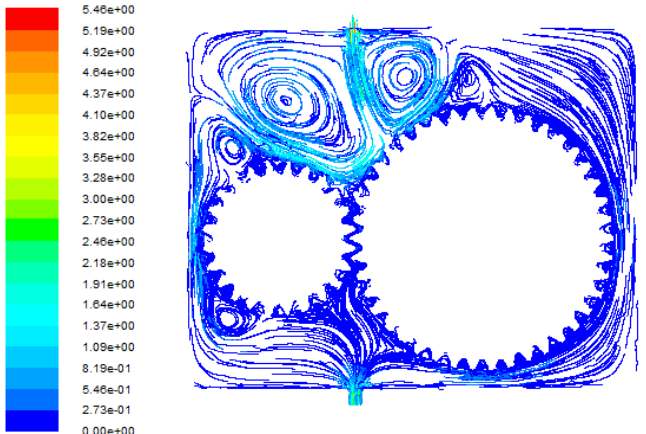

c)

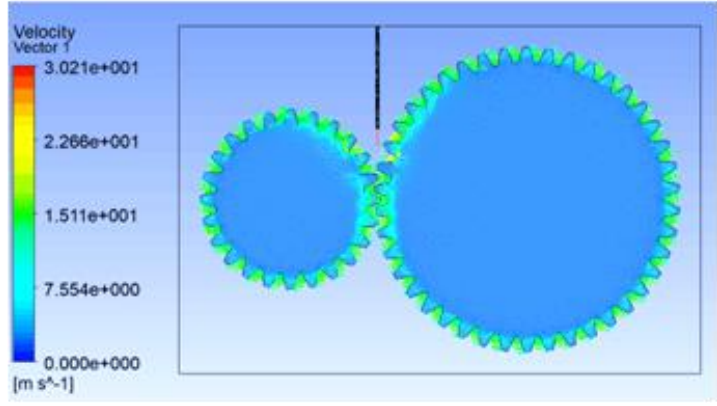

b)
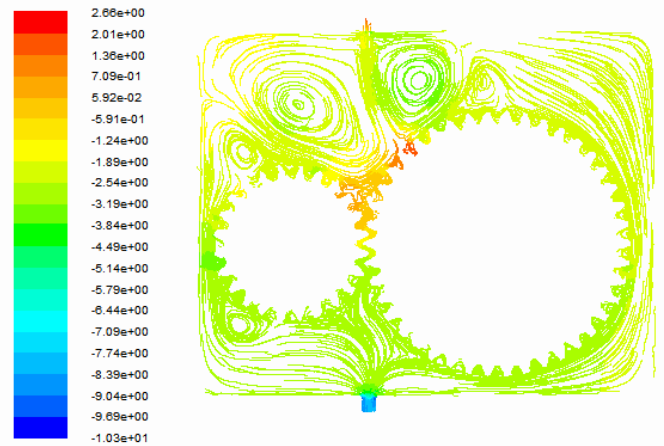

d)

Figure 4: Oil jet flow characteristic simulations when considering the spin-flow effect: a) flow field velocity vector; b) velocity vector near gears; c) velocity streamline; d) pressure streamline.

\subsection{Oil jet simulation with consideration of spin-flow effect}

To verify the spin-flow effect on the oil distribution and introduce an optimal nozzle position layout under the spin-flow effect, four different simulation models with different nozzle positions, as given in Table III, were established. According to the theoretical calculation method for the impingement depth, these four different models should have the same impingement depth despite their different nozzle positions.

Table III: Models with different nozzle positions but the same impingement depth.

\begin{tabular}{|c|c|c|}
\hline $\begin{array}{c}\text { Simulation } \\
\text { model }\end{array}$ & $\begin{array}{c}\text { Inclination angle } \\
\text { (degree) }\end{array}$ & $\begin{array}{c}\text { Offset distance } \\
(\mathrm{mm})\end{array}$ \\
\hline 1 & 0 & -1.15 \\
\hline 2 & -5 & -8.00 \\
\hline 3 & -7.5 & -11.40 \\
\hline 4 & -10 & -14.80 \\
\hline
\end{tabular}

Fig. 5 shows the oil volume contour simulation results. Table IV gives the corresponding oil volumes and pressures simulation values.

The jet flow trajectories have obviously been influenced by the spin flow towards to the big gears, resulting in reduced lubrication oil in the pinions. Although their theoretical oil impingement depths are identical according to the computational method, their lubrication effects judged by the oil volume and pressure distributions are different, which further proves the influence of spin flow. Meanwhile, an optimal design scheme for the nozzle positions can be obtained in which the nozzle should have a proper inclination angle and offset distance towards to the pinion. 

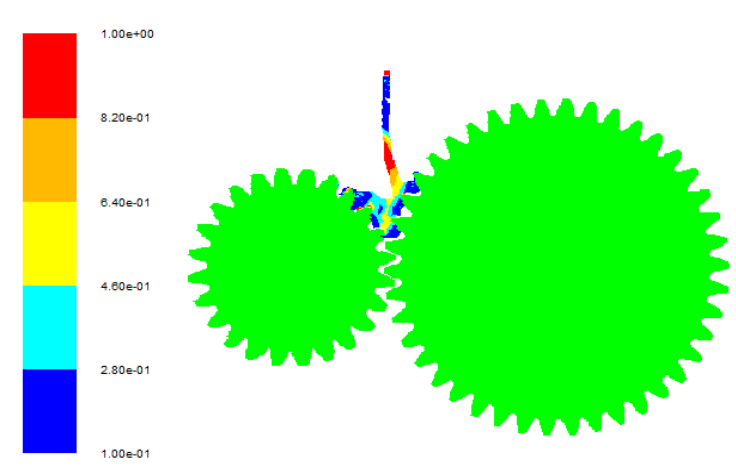

a)
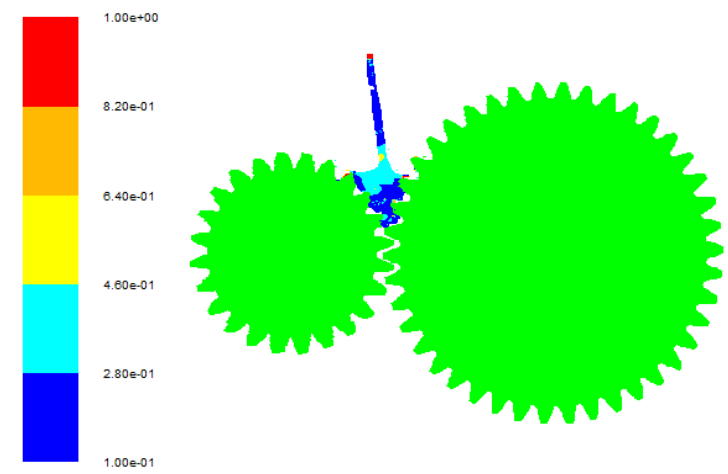

c)
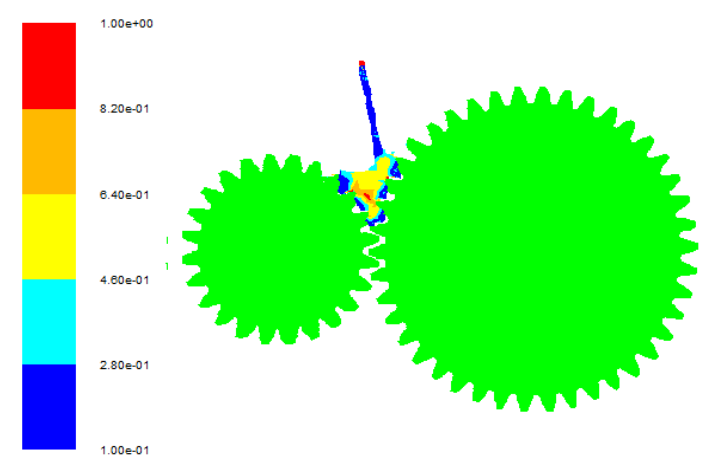

b)
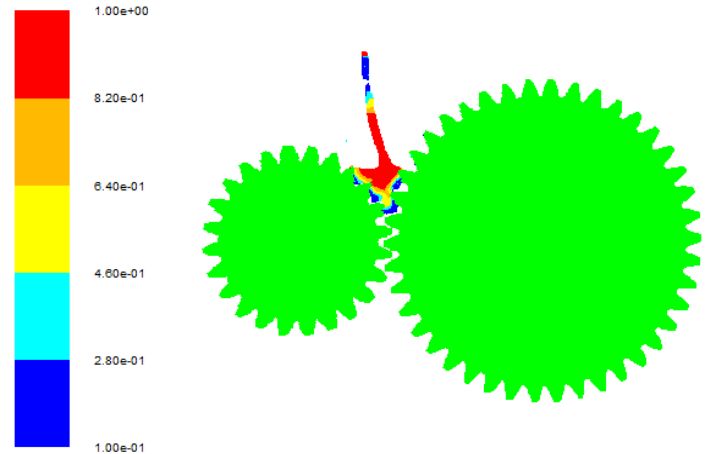

d)

Figure 5: Oil volume contour simulations for models with different nozzle positions but the same impingement depth: a) Model 1; b) Model 2; c) Model 3; d) Model 4.

Table IV: Oil volumes and oil pressures simulation results.

\begin{tabular}{|c|c|c|}
\hline Simulation Model & Oil Volume & Oil Pressure (Pa) \\
\hline 1 & 0.065 & 899.0 \\
\hline 2 & 0.082 & 919.2 \\
\hline 3 & 0.095 & 1255.2 \\
\hline 4 & 0.080 & 909.4 \\
\hline
\end{tabular}

\section{EXPERIMENTAL VALIDATIONS}

The experimental system as shown in Fig. 6 was built for investigating the oil jet lubrication performance for high-speed gears and for validating the simulation results. The system included an oil supply subsystem, a driving subsystem, a load subsystem, a test gearbox with a nozzle position control apparatus and a measurement subsystem. The nozzle positions were adjusted to be consistent with the above simulation models. The jet flow states were photographed by a high-speed camera, while the gear surface temperatures were measured by a thermal infrared imager. Table $\mathrm{V}$ lists the measured temperatures with comparisons to the oil volume and pressure distributions obtained in the simulations.

The results show that the higher the oil volume and pressure in the numerical simulations, the lower the gear surface temperatures measured in the tests, and the results can be mutually validated. Meanwhile, an optimal nozzle position layout design scheme can be obtained in which the nozzle tilts at a proper angle and is offset at a proper distance towards the pinion. In this research, for such gear pair parameters, the optimal inclination angle for the nozzle towards to the pinion is approximately 7.5 degrees, while the optimal offset distance is roughly $11.5 \mathrm{~mm}$, which are used for optimal oil lubrication performance. 


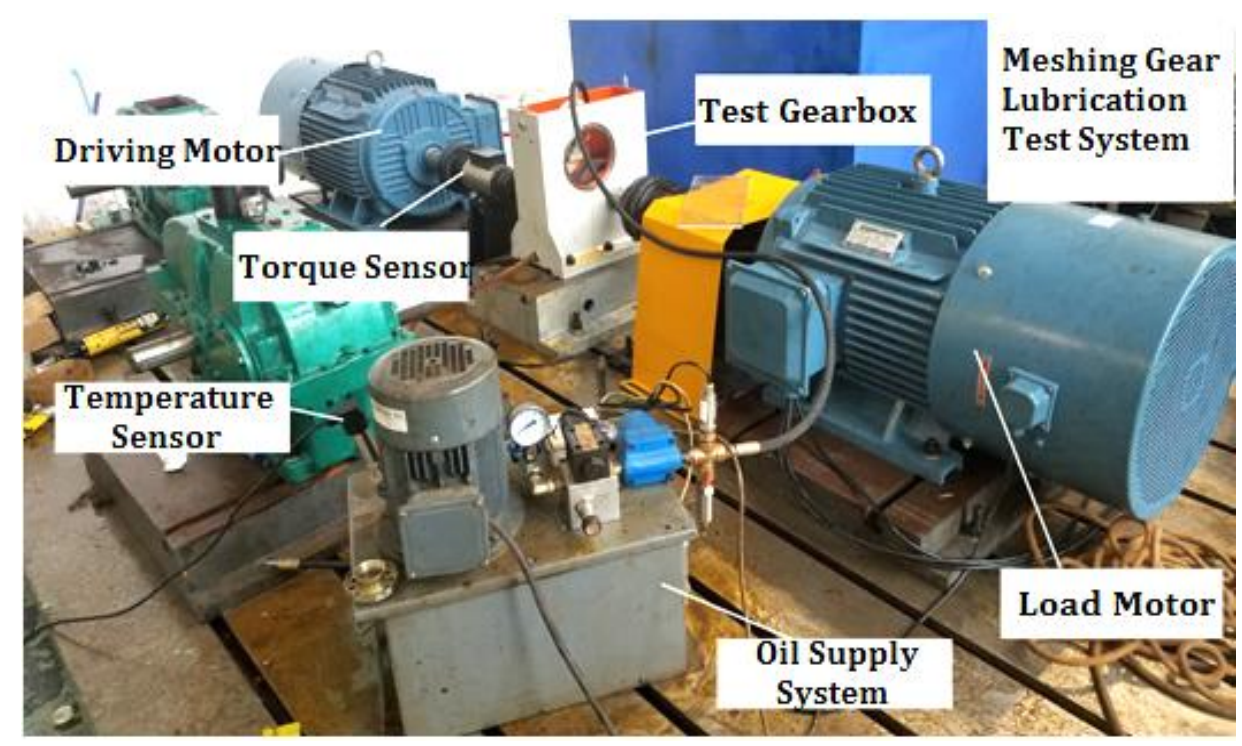

Figure 6: Gear oil jet lubrication test system.

Table V: Temperatures measured on gear surfaces in the four tests.

\begin{tabular}{|c|c|c|c|}
\hline Test model & $\begin{array}{c}\text { Temperature } \\
\text { (degrees) }\end{array}$ & Oil volume & $\begin{array}{c}\text { Oil pressure } \\
(\mathrm{Pa})\end{array}$ \\
\hline 1 & 81.7 & 0.065 & 899.0 \\
\hline 2 & 77.6 & 0.082 & 919.2 \\
\hline 3 & 76.3 & 0.095 & 1255.2 \\
\hline 4 & 77.1 & 0.080 & 909.4 \\
\hline
\end{tabular}

\section{CONCLUSIONS}

The major conclusions of this work are as follows:

(1) A 3D oil-air two-phase mixture flow numerical simulation model for oil jet lubrication on a high-speed meshing gear pair has been established. The simulations with different nozzle positions show that the lubrication performance can be predicted by the oil volume and pressure distributions on the gear surfaces that are related to the oil impingement depths on the same surfaces. The greater the impingement depth, the higher the oil volume and pressure, which result in better lubrication and cooling effects.

(2) The spin-flow effect generated by a high-speed rotating gear pair on the jet flow trajectory was taken into account in the numerical simulation. Due to the spin flow, the oil jet flow will deviate from its predetermined trajectory and towards to the big gear, which will accurately influence the oil spray into the meshing area and result in failure of lubrication and cooling.

(3) Considering the spin-flow effect, the oil jet simulations performed with different nozzle positions layouts resulted in an optimal layout design scheme for the nozzle positions. The results indicate that the nozzle should tilt at a proper angle and offset a proper distance towards to the pinion.

(4) Gear oil jet lubrication tests were performed, and the results proved the computational correctness of the simulation models. Combined with the simulations, an optimal nozzle position layout design scheme was obtained to get the optimal lubrication effect with a tilted nozzle angle towards to the pinion at approximately 7.5 degrees with an offset distance of roughly $11.5 \mathrm{~mm}$. 


\section{ACKNOWLEDGEMENTS}

This research is supported by the National Defence Preliminary Research Project (Grant No. 8130208). The authors would like to thank from the anonymous reviewers for their comments that improved the quality of this paper.

\section{REFERENCES}

[1] McCain, J. W; Alsandor, E. (1966). Analytical aspects of gear lubrication on the disengaging side, ASLE Transactions, Vol. 9, No. 1, 202-211, doi:10.1016/0043-1648(66)90083-4

[2] Akin, L. S.; Mross, J. J.; Townsend, D. P. (1975). Study of lubricant jet flow phenomena in spur gears, Journal of Lubrication Technology, Vol. 97, No. 2, 283-288, doi:10.1115/1.3452576

[3] Townsend, D. P; Akin, L. S. (1981). Analytical and experimental spur gear tooth temperature as affected by operating variables, Journal of Mechanical Design, Vol. 103, No. 1, 219-226, doi: $10.1115 / 1.3254868$

[4] Hirt, C. W.; Nichols, B. D. (1981). Volume of fluid (VOF) method for the dynamics of free boundaries, Journal of Computational Physics, Vol. 39, No. 1, 201-225, doi:10.1016/ 0021-9991(81)90145-5

[5] Akin, L. S.; Townsend, D. P. (1983). Into mesh lubrication of spur gears with arbitrary offset oil jet. Part 1: For jet velocity less than or equal to gear velocity, Journal of Mechanisms, Transmissions, and Automation in Design, Vol. 105, No. 4, 713-718, doi:10.1115/1.3258541

[6] Akin, L. S.; Townsend, D. P. (1983). Into mesh lubrication of spur gears with arbitrary offset oil jet. Part 2: For jet velocities equal to or greater than gear velocity, Journal of Mechanisms, Transmissions, and Automation in Design, Vol. 105, No. 4, 719-724, doi:10.1115/1.3258542

[7] Akin, L. S.; Townsend, D. P. (1989). Lubricant jet flow phenomena in spur and helical gears with modified addendums - for radially directed individual jets, Proceeding of the $5^{\text {th }}$ International Power Transmission and Gearing Conference, 367-374

[8] Akin, L. S.; Townsend, D. P. (1985). Lubricant jet flow phenomena in spur and helical gears with modified center distances and/or addendums - for out-of-mesh conditions, Journal of Mechanisms, Transmissions, and Automation in Design, Vol. 107, No. 1, 24-30, doi: $10.1115 / 1.3258686$

[9] Handschuh, R. F. (1992). Effect of lubricant jet location on spiral bevel gear operating temperatures, Proceedings of the $6^{\text {th }}$ International Power Transmission and Gearing Conference, $1-8$

[10] Fondelli, T.; Andreini, A.; Da Soghe, R.; Facchini, B.; Cipolla, L. (2015). Numerical simulation of oil jet lubrication for high speed gears, International Journal of Aerospace Engineering, Vol. 2015, Paper ID 752457, 13 pages, doi:10.1155/2015/752457

[11] Massini, D.; Fondelli, T.; Facchini, B.; Tarchi, L.; Leonardi F. (2016). High speed visualizations of oil jet lubrication for aero-engine gearboxes, Energy Procedia, Vol. 101, 1248-1255, doi:10.1016/j.egypro.2016.11.140

[12] Wang, Y.-Z.; Niu, W.-T.; Wei, S.; Song, G.-H. (2015). Influence of spin flow on lubricating oil jet - Design method of oil spray parameters to high speed spur gears, Tribology International, Vol. 92, 290-300, doi:10.1016/j.triboint.2015.07.017

[13] Li, H. X.; Li, B.; Choi, J.; Heo, J.; Kim, I. (2016). Analysis of a novel nozzle used for pulse jet filtration using CFD simulation method, International Journal of Simulation Modelling, Vol. 15, No. 2, 262-274, doi:10.2507/IJSIMM15(2)6.334

[14] Wang, Y.-Z.; Song, G.-H.; Niu, W.-T.; Chen, Y.-Y. (2018). Influence of oil injection methods on the lubrication process of high speed spur gears, Tribology International, Vol. 121, 180-189, doi:10.1016/j.triboint.2018.01.062

[15] Wang, Y.-Z.; Song, G.-H.; Niu, W.-T.; Chen, Y.-Y. (2018). Optimized design of spray parameters of oil jet lubricated spur gears, Tribology International, Vol. 120, 149-158, doi:10.1016/j.triboint.2017.12.042 